\title{
+TIP EB1 downregulates paclitaxel-induced proliferation inhibition and apoptosis in breast cancer cells through inhibition of paclitaxel binding on microtubules
}

\author{
GEETHU EMILY THOMAS, JAMUNA S. SREEJA, K.K. GIREESH, HINDOL GUPTA and TAPAS K. MANNA
}

School of Biology, Indian Institute of Science Education and Research,

CET Campus, Thiruvananthapuram 695016, Kerala, India

Received July 13, 2014; Accepted September 9, 2014

DOI: $10.3892 /$ ijo.2014.2701

\begin{abstract}
Microtubule plus-end-binding protein (+TIP) EB1 has been shown to be upregulated in breast cancer cells and promote breast tumor growth in vivo. However, its effect on the cellular actions of microtubule-targeted drugs in breast cancer cells has remained poorly understood. By using cellular and biochemical assays, we demonstrate that EB1 plays a critical role in regulating the sensitivity of breast cancer cells to anti-microtubule drug, paclitaxel (PTX). Cell viability assays revealed that EB1 expression in the breast cancer cell lines correlated with the reduction of their sensitivity to PTX. Knockdown of EB1 by enzymatically-prepared siRNA pools (esiRNAs) increased PTX-induced cytotoxicity and sensitized cells to PTX-induced apoptosis in three breast cancer cell lines, MCF-7, MDA MB-231 and T47D. Apoptosis was associated with activation of caspase-9 and an increase in the cleavage of poly(ADP-ribose) polymerase (PARP). p53 and $\mathrm{Bax}$ were upregulated and $\mathrm{Bcl} 2$ was downregulated in the EB1-depleted PTX-treated MCF-7 cells, indicating that the apoptosis occurs via a p53-dependent pathway. Following its upregulation, the nuclear accumulation of p53 and its association with cellular microtubules were increased. EB1 depletion increased PTX-induced microtubule bundling in the interphase cells and induced formation of multiple spindle foci with abnormally elongated spindles in the mitotic MCF-7 cells, indicating that loss of EB1 promotes PTX-induced stabilization of microtubules. EB1 inhibited PTX-induced microtubule polymerization and diminished PTX binding to microtubules in vitro, suggesting that it modulates the binding sites of PTX at the growing microtubule ends. Results demonstrate that EB1 downregulates inhibition of PTX-induced proliferation and apoptosis in breast cancer cells through a mechanism
\end{abstract}

Correspondence to: Dr Tapas K. Manna, School of Biology, Indian Institute of Science Education and Research, CET Campus, Thiruvananthapuram 695016, India

E-mail:tmanna@iisertvm.ac.in

Key words: EB1, microtubule, paclitaxel, apoptosis, p53 in which it impairs PTX-mediated stabilization of microtubule polymerization and inhibits PTX binding on microtubules.

\section{Introduction}

Breast cancer is among the leading causes of cancer mortality and accounts for more than 400,000 deaths annually worldwide (1). The introduction of new chemotherapeutic regimens in recent years has modestly improved the survival rate of patients, but there are still major obstacles that must be overcome before this disease can be successfully treated $(2,3)$. One of the major clinical issues is the development of drug resistance, which accounts for a poor response and reduces the overall survival rate in patients $(4,5)$. Among the drugs used for treating breast cancer, the ones most commonly used belong to the taxane group of agents, which kill tumor cells by targeting cellular microtubules $(6,7)$. Similar to other classes of agents, however, a major drawback of taxane chemotherapy is that tumor cells can develop resistance to these drugs (5,8-10).

Paclitaxel (PTX) is a prototype of microtubule-stabilizing agents that disrupt cellular microtubule function by stabilizing the microtubule assembly dynamics (6). Specifically, it suppresses the growth and shortening dynamics of microtubules through its interaction with the plus-end of the microtubule (11). As a result, it disrupts the normal spindle architecture of the cell, which leads to chromosome segregation defects, mitotic arrest and eventually apoptosis $(12,13)$. Earlier studies have demonstrated that there is a close relationship between microtubule dynamics and PTX resistance in cancer cells (14-20).

Microtubules associate with a specialized class of proteins, known as the plus-end-binding proteins (+TIPs), that localize to the growing plus-ends of microtubules and regulate numerous plus-end-mediated processes. Recent studies have emphasized the central role of end-binding (EB) family proteins among the +TIPs (21-25). Mammals contain three EBs, EB1, EB2, and EB3 with $~ 57-66 \%$ sequence identity and are encoded by separate genes (26). EBs play critical roles in the regulation of microtubule dynamics (27-30). Recently, analysis using reconstituted microtubules showed that EBs can modulate the dynamics of PTX-treated microtubules. Specifically, EB3 has been shown to stimulate catastrophe 
events and to rescue growth of PTX-treated microtubules, indicating that it suppresses PTX's ability to stabilize microtubule dynamics (31). Among the EB family proteins, EB1 was focused on previously as it is highly conserved compared to other EB members and is ubiquitously expressed in all cell types (26). High resolution structural analysis showed that EB1 alters the structure of microtubule plus-ends (32). Consistent with its ability to modulate structure-function of microtubules, EB1 plays essential roles in mitosis (33-36). Recently, overexpression of EB1 has been shown to stimulate cell growth in cultured human breast cancer cells, indicating that it plays an important role in stimulation of cell proliferation $(37,38)$.

In addition to its microtubule regulatory roles, EB1 has been strongly linked to tumorigenesis. It binds to adenomatous polyposis coli (APC), a major tumor suppressor in colon. Mutations in the EB1-binding region of APC are commonly found in colon cancer cells (39). Recent proteomic and biochemical analyses have shown that there is a high EB1 expression level in various human carcinomas and breast cancer cells $(38,40,41)$. Consistent with a higher expression level in breast cancer cells, EB1 has also been shown to be upregulated in breast cancer patients (38). Specifically, its expression level appears to be correlated with the clinicopathological signature of the tumor malignancy in patients (38). This study has also shown that EB1 enhances breast tumor growth in nude mice (38).

Because of the close relationship between the regulation of microtubule dynamics by EB1 and PTX, and the correlation between EB1 expression and breast cancer, we speculated that EB1 could regulate PTX-induced cytotoxicity and PTX-mediated microtubule stabilization in breast cancer cells. In the present study, we investigated the role of EB1 in regulating PTX-induced cytotoxicity and microtubule stabilization in breast cancer cells. Our results demonstrate that suppression of EB1 sensitizes cells to PTX-induced cytotoxicity and apoptosis. Additional results revealed details of the underlying mechanism associated with the regulation of PTX sensitivity by EB1.

\section{Materials and methods}

Reagents and antibodies. PTX, vinblastine (VIN), cisplatin, propidium iodide (PI), DAPI, GTP, PIPES, EGTA, reagents for the methylthiotetrazol (MTT) assay and the Annexin V apoptosis detection kit were obtained from Sigma (St. Louis, MO, USA). Dulbecco's modified Eagle's medium (DMEM), Leibovitz (L-15) medium, RPMI-1640 medium, DMEM-F12 (1:1) medium supplemented with HEPES and fetal bovine serum (FBS) were purchased from HiMedia Laboratories (Mumbai, India). Rhodamine labeled tubulin was obtained from Cytoskeleton, Inc. (Denver, CO, USA), and Oregon green 488-labeled PTX (Ore-PTX) was obtained from Invitrogen Life Technologies (Carlsbad, CA, USA). Monoclonal antibodies against EB1, actin and BubR1 were obtained from BD Biosciences (San Jose, CA, USA). Mouse monoclonal antibodies against $\alpha$-tubulin and p53 and the rabbit polyclonal anti-EB1 were obtained from Sigma. Mouse monoclonal anti-Bax, rat monoclonal anti- $\alpha$-tubulin and rabbit polyclonal anti-Bcl2, anti-caspase-9 and anti-PARP were obtained from Abcam (Cambridge, MA, USA). Rabbit polyclonal p21 antibody was obtained from Cell Signaling Technology, Inc. (Danvers, MA, USA). FITC, TRITC and peroxidase conjugated secondary antibodies were obtained from Jackson ImmunoResearch (West Grove, PA, USA).

Cell culture, transfection with ribonuclease III-prepared siRNA pools (esiRNA). MCF-7, MDA MB-231 and T47D cells originally obtained from ATCC (Manassas, VA, USA) were cultured in DMEM, L-15, and RPMI-1640 media, respectively, which were supplemented with $10 \%$ FBS, 2 mM L-glutamine, $1.5 \mathrm{mg} / \mathrm{ml}$ sodium bicarbonate, $100 \mu \mathrm{g} / \mathrm{ml}$ penicillin and $100 \mu \mathrm{g} / \mathrm{ml}$ streptomycin. MCF-10 A cells were grown as a monolayer culture in DMEM-F12 medium supplemented with 5\% donor horse serum (Invitrogen Life Technologies), $20 \mathrm{ng} / \mathrm{ml}$ epidermal growth factor (EGF), $10 \mu \mathrm{g} / \mathrm{ml}$ insulin, $0.5 \mu \mathrm{g} / \mathrm{ml}$ hydrocortisone, $100 \mathrm{ng} / \mathrm{ml}$ cholera toxin (all from Sigma), $100 \mu \mathrm{g} / \mathrm{ml}$ penicillin and $100 \mu \mathrm{g} / \mathrm{ml}$ streptomycin (42).

To downregulate protein expression, we used ribonuclease III-prepared small interfering RNA pools, which ensure the efficient knockdown of proteins with minimum off-target effects compared with single siRNAs $(43,44)$. esiRNA consists of enzymatically-prepared siRNA pools comprised of a heterogeneous mixture of siRNAs which target the same mRNA sequence of the gene (43). Cells at $\sim 50 \%$ confluence were transfected with either EB1 esiRNA (cat. no. EHU045671; Sigma) against the 331-807 nucleotide region of EB1 (NM_012325.2) or luciferase control esiRNA (cat. no. EHUFLUC; Sigma) using either oligofectamine (for MCF-7 cells) or lipofectamine (for T47D and MDA MB-231 cells) as the vehicle.

Plasmids and proteins. pEGFP-EB1 was used as the template for PCR amplification of the complete coding sequence of the human EB1 (NM_012325.2) gene. The amplified product was ligated into the pET-28a (Novagen, Inc., Madison, WI, USA) expression vector and transformed into BL21-(DE3) cells. The 6-His-tagged EB1 was expressed under $1 \mathrm{mM}$ IPTG and then purified through Nickel-NTA (28). Tubulin was purified from goat brains by repetitive cycles of polymerization and depolymerization (45). Protein concentrations were estimated by the Bradford method using BSA as the standard (46).

Cell proliferation and apoptosis assays. The effect of PTX on cell viability was measured by MTT assay as previously described (47). The cells at $\sim 60 \%$ confluence were treated with gradients of PTX concentrations (1-200 nM), and allowed to grow for the next $48 \mathrm{~h}$ prior to measuring cell viability using MTT assay in the Multi-Mode Microplate Reader, SpectraMax 5 (Molecular Devices, Sunnyvale, CA, USA). The percentage of viable cells as a function of drug concentration was plotted to determine the drug concentration needed to inhibit cell viability by $50 \%$, half inhibitory concentrations $\left(\mathrm{IC}_{50}\right)$. For determination of $\mathrm{IC}_{50}$ values in the esiRNA-treated cells, the cells after $24 \mathrm{~h}$ of transfection with esiRNA were treated with gradients of PTX concentrations (5-200 nM) and then incubated for another $48 \mathrm{~h}$ prior to measuring cell viability using the MTT assay. For the apoptosis assay, after $24 \mathrm{~h}$ of transfection with esiRNA, the cells were treated with PTX $(10 \mathrm{nM})$ for the next $48 \mathrm{~h}$. Apoptosis was measured using the Annexin V-FITC apoptosis assay kit followed by flow cytometric analysis using the FACSAria III (BD Biosciences). The quadrants of the 
raw sample data were determined by comparing the data of unstained cells. Data were analyzed using FlowJo software. Percentages of apoptosis were quantified from the sum of first (Q1) and second (Q2) quadrant. Total cell death was quantified from the sum of Q1, Q2 and the third quadrant (Q3). Apoptosis was also detected using immunofluorescence-based imaging. The cells were grown on coverslips, washed with PBS and then treated with binding buffer containing Annexin V FITC and PI for $10 \mathrm{~min}$ (48). The relative levels of Annexin V and PI staining were determined using confocal microscopy.

Microtubule pull-down assay from cell lysate. MCF-7 cells were lysed in BRB80 buffer, pH 6.8 supplemented with a $1 \mathrm{X}$ protease inhibitor cocktail and $0.1 \%$ Triton $\mathrm{X}-100$ and then centrifuged at $15,000 \mathrm{rpm}$ for $15 \mathrm{~min}$ at $4^{\circ} \mathrm{C}$. Exogenously purified bovine tubulin $(2 \mu \mathrm{M})$ and $1 \mathrm{mM}$ GTP were then added to the cell lysates, and the reaction mixture was polymerized at $37^{\circ} \mathrm{C}$ for $15 \mathrm{~min}$ (49). Microtubules were pelleted at $100,000 \mathrm{x} \mathrm{g}$ for $40 \mathrm{~min}$ at $35^{\circ} \mathrm{C}$ and washed with warm BRB80 buffer. The pellet was treated with 4 X SDS sample buffer, and proteins were detected by western blot analysis.

Western blot analysis. Protein samples and cell lysates were run on SDS-PAGE, and the protein bands were transferred onto polyvinylidene fluoride (PVDF) membranes. Target proteins were detected by incubating the membranes in the appropriate primary antibodies and then incubating them in the appropriate HRP-conjugated secondary antibodies. Densitometric analyses of the blots were performed using the Quantity One software (Bio-Rad, Hercules, CA, USA).

Immunofluorescence microscopy and image analysis. Cells fixed in either methanol at $-20^{\circ} \mathrm{C}$ or $3.7 \%$ paraformaldehyde were washed with PBS containing $2 \%$ bovine serum albumin and $0.5 \%$ Triton X-100. The cells were then incubated in primary antibody for $1 \mathrm{~h}$ and then incubated in secondary antibody and DAPI for 45 and $1 \mathrm{~min}$, respectively. Coverslips were mounted using ProLong Gold (Invitrogen Life Technologies), and the images (63X) were captured using a Leica SP5 laser confocal microscope. The intensity measurements were taken using the system run software provided by Leica. Briefly, intensity per pixel was quantified by selecting regions of interest (ROI) of equal size in all the images for comparison.

Microtubule polymerization and PTX microtubule-binding assay. Reaction mixtures containing tubulin $(15 \mu \mathrm{M})$ and the desired concentration of EB1 were polymerized in BRB80 buffer (80 mM PIPES, $2 \mathrm{mM}$ EGTA and $1 \mathrm{mM} \mathrm{MgCl}$ ), pH 6.8, containing $1 \mathrm{mM}$ GTP and $0.1 \mu \mathrm{M}$ PTX. Polymerization was monitored by measuring the turbidity of the reaction mixtures at $360 \mathrm{~nm}$. For the quantitative estimation of microtubules, the reaction mixtures were passed through a $15 \%$ glycerol cushion by centrifugation at $100,000 \mathrm{~g}$ after $30 \mathrm{~min}$ of polymerization. The pellets were resuspended in cold buffer, and the proteins were run on $10 \%$ SDS-PAGE and then subjected to Coomassie staining. For the quantitative analysis of PTX binding to microtubules, tubulin $(10 \mu \mathrm{M})$ was polymerized into microtubules in vitro in BRB80 buffer containing $10 \%$ glycerol and $1 \mathrm{mM}$ GTP for $15 \mathrm{~min}$ at $37^{\circ} \mathrm{C}$. Next, Ore-PTX (20 nM) was added either to the control microtubules or the microtubules pre-incubated with EB1 $(20-200 \mathrm{nM})$ for $15 \mathrm{~min}$. The reaction mixtures were incubated for another $15 \mathrm{~min}$ prior to centrifugation through a $15 \%$ sucrose cushion at 100,000 g. The microtubule pellets were resuspended in ice-cold BRB80 buffer. The binding of Ore-PTX to the microtubules was determined by measuring the fluorescence intensity of Ore-PTX present in the microtubule solutions. Fluorescence measurements were taken using a fluorescence spectrophotometer (Horiba FluoroLog-3) with an excitation at $488 \mathrm{~nm}$ and an emission in the 500-560 $\mathrm{nm}$ range. The percentage of Ore-PTX binding on microtubules inhibited by EB1 was estimated by comparing the fluorescence values at $525 \mathrm{~nm}$ of the EB1 containing Ore-PTX-treated samples with the Ore-PTX only treated control sample. All fluorescence measurements were taken using a $1-\mathrm{cm}$ path length cuvette. The pelleted microtubule solutions were also run through $10 \%$ SDS-PAGE.

Statistical analysis. Results are presented as the mean \pm standard error (SE). Statistical significance was set at $\mathrm{p}<0.05$. One-way analysis of variance (ANOVA) was used for statistical analysis on EB1 expression levels and $\mathrm{IC}_{50}$ values in different cell lines. The comparison of differences between control and the treated groups was performed using a two-tailed Student's t-test. The data were plotted using Origin 8.

\section{Results}

EB1 expression negatively correlates with PTX sensitivity in breast cancer cell lines. We examined the expression of EB1 by immunoblotting in three breast cancer cell lines, the human breast adenocarcinoma cells MCF-7, the metastatic human breast adenocarcinoma MDA MB-231cells, and the human ductal breast epithelial tumor T47D cells. Two non-tumorigenic cell lines, mammary MCF-10 A and the kidney epithelial HEK-293 were used as control. A significantly high EB1 expression level was observed in all three breast cancer cell lines compared with the normal MCF-10 A and HEK-293 cells (Fig. 1A and B). EB1 expressions in the breast cancer cell lines were several folds higher as compared with the MCF-10 A and HEK-293 cells. Statistical analyses were performed based on the results of two independent western blot analysis images, as described in Materials and methods. These results were in good agreement with previously published results on EB1 expression in breast cancer cells (38). We then examined if the EB1 expression level correlates with the sensitivity of these cells to PTX. To determine the sensitivity of these cells to PTX, we performed in vitro cell viability assays. Cells treated with gradients of PTX concentrations (1-200 $\mathrm{nM}$ ) were analyzed for cell viability by the MTT assay. The $\mathrm{IC}_{50}$ values of PTX, which stand for the concentration of PTX needed to suppress cell viability by $50 \%$, in the cell lines were then determined. Strikingly, we noted that MCF-7, MDA MB-231 and T47D cells had much higher $\mathrm{IC}_{50}$ values than the control MCF-10 A cells (Fig. 1C). Consistent with the previously published data (50), MCF-10 A cells exhibited a very low $\mathrm{IC}_{50}$ of $\sim 6 \mathrm{nM}$. However, the $\mathrm{IC}_{50}$ values for MCF-7, MDA MB-231 and T47D cells were increased to 40,28 and $62 \mathrm{nM}$, respectively with a range of 5-10-fold increase compared to MCF-10 A. Thus, the expression levels of EB1 correlated with the $\mathrm{IC}_{50}$ values of PTX. 
A $\quad$ Expt 1

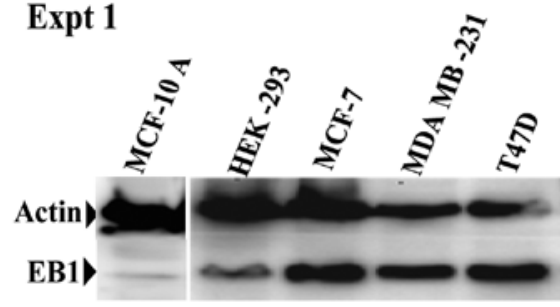

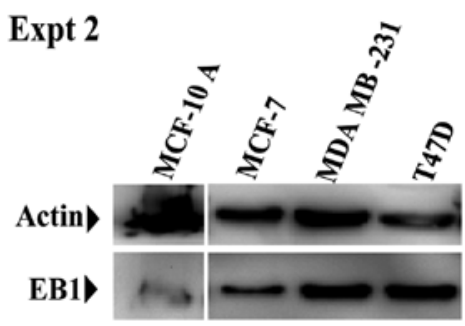

C
B

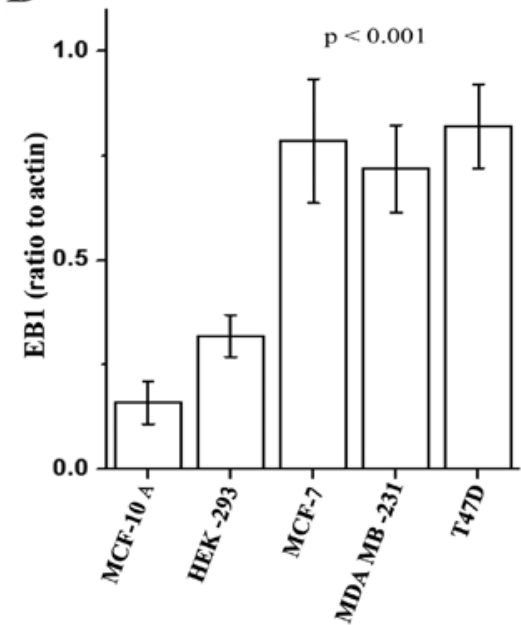

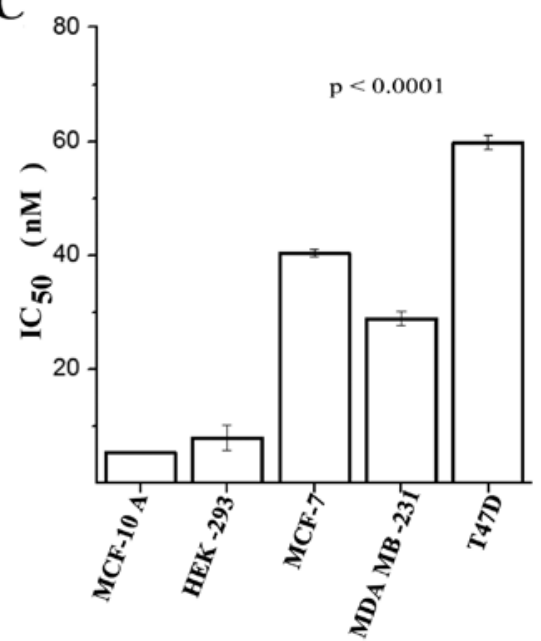

Figure 1. Correlation between paclitaxel (PTX) sensitivity and EB1 expression level in breast cancer cell lines. (A) EB1 expression in the breast cancer cell lines MCF-7, MDA MB-231 and T47D were assessed by western blot analysis. Imagesof western blot analysis of two independent experiments are shown (Expt 1 and 2). Expression in non-tumorigenic MCF-10 A and HEK-293 cells are shown as control. (B) The bar plot shows quantification of EB1 expression in the cell lines from two independent experiments. Data are mean \pm standard error (SE). (C) Plot shows half inhibitory concentration (IC s0 $_{50}$ values of PTX in proliferation inhibition in the cell lines shown in (A). Data are mean \pm SE (three experiments). Statistical analyses were performed using analysis of variance (ANOVA).

A

MCF-7 MDA MB-231 T47D
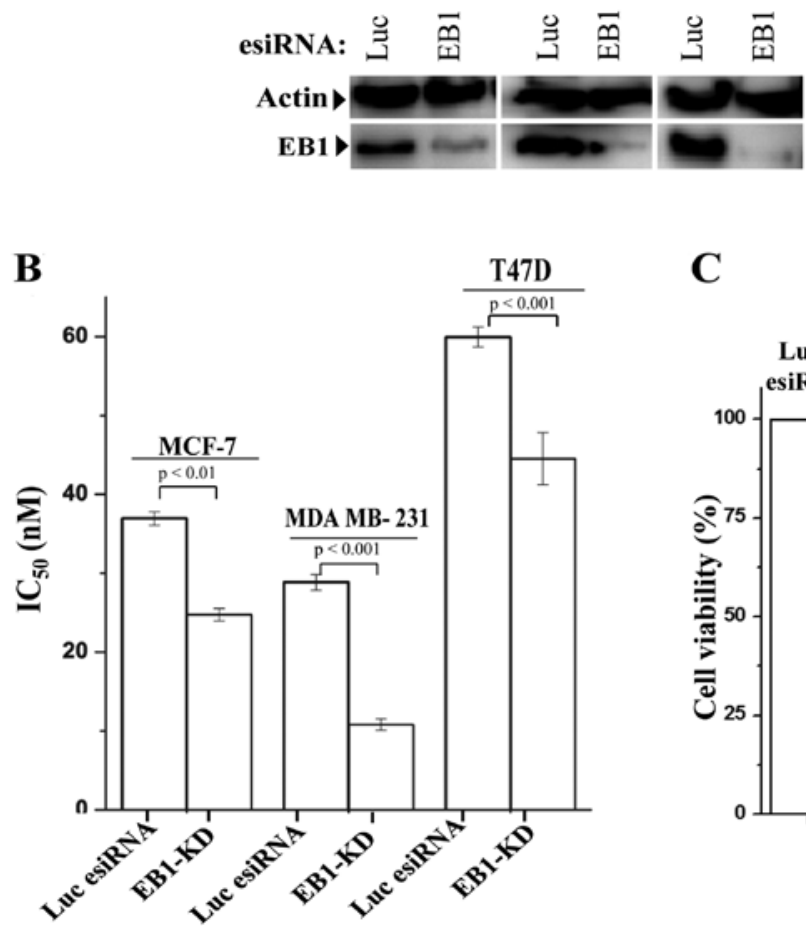

C

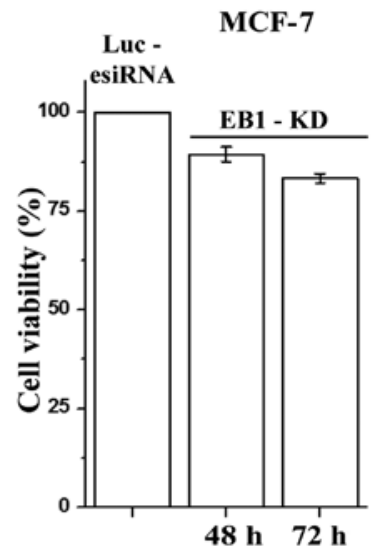

Figure 2. EB1 knockdown (EB1-KD) increased the ability of paclitaxel (PTX) to inhibit cell viability in breast cancer cells. (A) Expressions of EB1 after $72 \mathrm{~h}$ of EB1 esiRNA (enzymatically-prepared siRNA pools) or luciferase esiRNA treatment to MCF-7, MDA MB-231 and T47D cells are shown by western blot analysis. (B) Plot shows the half inhibitory concentration $\left(\mathrm{IC}_{50}\right)$ values of PTX in the luciferase esiRNA treated vs. EB1-KD MCF-7, MDA MB-231 and T47D cells. IC $_{50}$ values were determined from the plot of percent cell viability in each cell line as a function of PTX concentrations, as described in Materials and methods. Data are average of three independent experiments [mean \pm standard error (SE)]. P-values were determined by Student's t-test. (C) Percent cell viability of control luciferase esiRNA-treated MCF-7 cells and the MCF-7 cells treated with EB1 esiRNA for 48 and $72 \mathrm{~h}$, respectively, are plotted. 

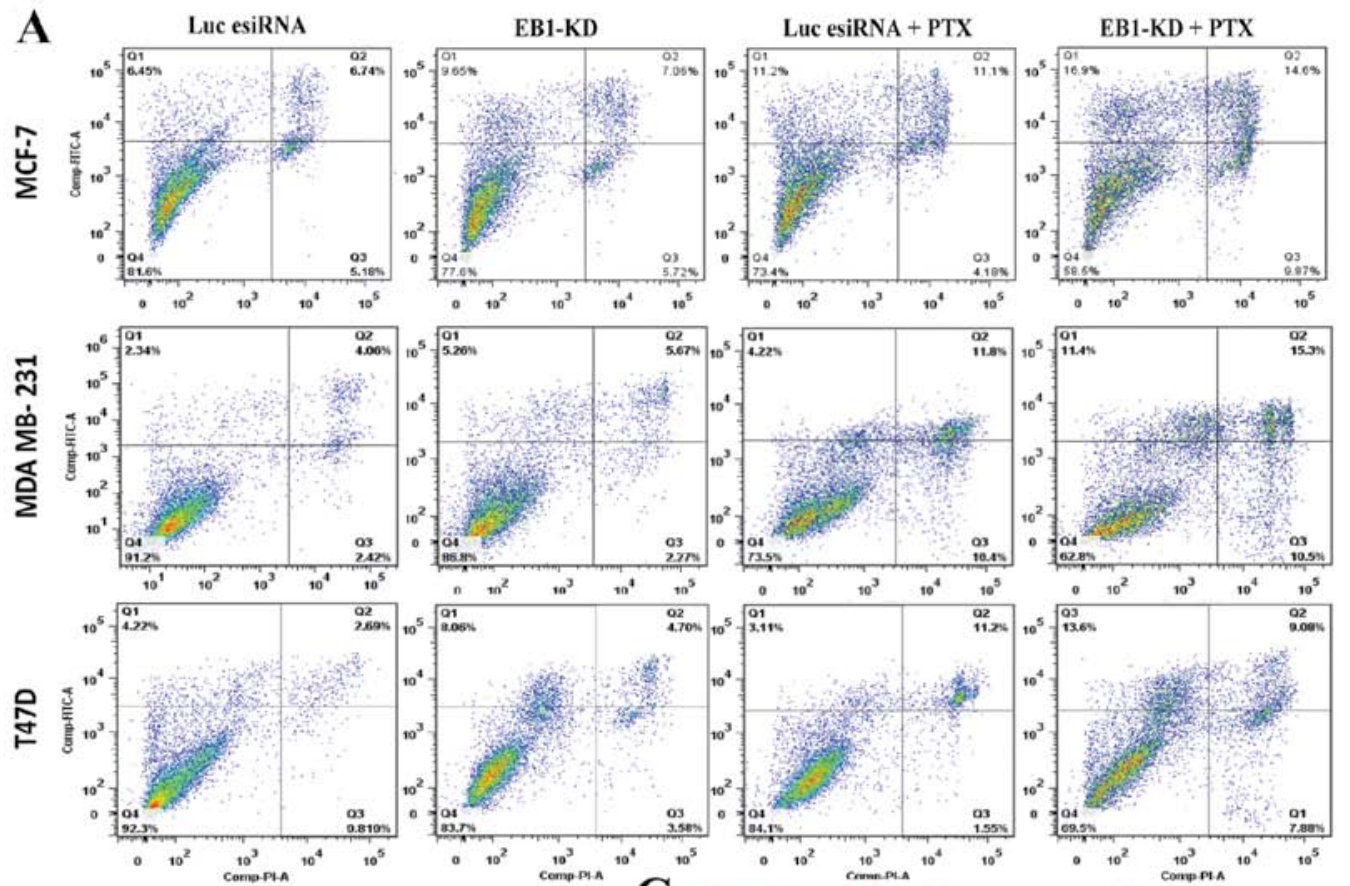

B
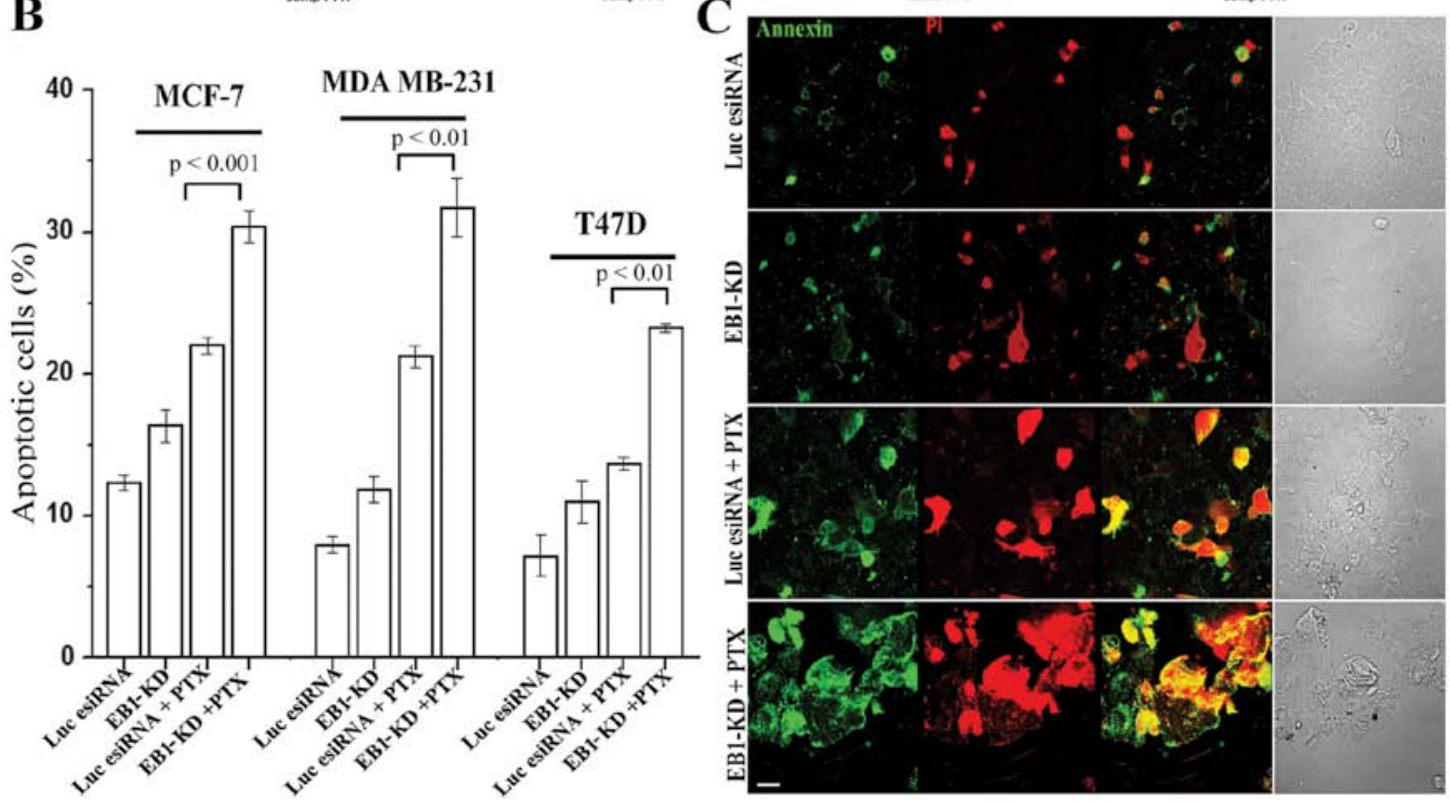

Figure 3. EB1 knockdown (EB1-KD) sensitizes breast cancer cells to paclitaxel (PTX) induced apoptosis. (A) MCF-7, MDA MB-231 and T47D cells, after treatment with EB1 esiRNA (siRNA pools) or luciferase esiRNA for $24 \mathrm{~h}$ followed by PTX $(10 \mathrm{nM})$ treatment for the next $48 \mathrm{~h}$, were analysed for apoptosis by Annexin V-propidium iodide (PI) assay. Flow cytometer data of PI vs. Annexin V-FITC are shown in the plots. (B) Percentages of apoptotic cells [sum of the first (Q1) and second (Q2) quadrant] are plotted. Data are average of three independent experiments [mean \pm standard error (SE)]. P-values were determined by Student's t-test. (C) Fluorescence images of Annexin V-FITC (green) and PI (red) in EB1-KD vs. luciferase esiRNA-treated MCF-7 cells in the presence or absence of PTX $(10 \mathrm{nM})$ are shown. Scale bar, $10 \mu \mathrm{m}$.

Unlike PTX, we did not observe any significant correlation between EB1 expression level in the cell lines and the cytotoxicity of VIN, a microtubule destabilizing agent (not shown).

\section{EB1 depletion increased PTX's ability to inhibit cell viability} in breast cancer cells. Next, we investigated the effect of EB1 depletion on PTX-induced cytotoxicity in the breast cancer cells. For efficient knockdown of EB1, we used ribonuclease III-prepared pool of siRNAs, as described in Materials and methods. Cells after treatment with EB1 esiRNA or control luciferase esiRNA for $24 \mathrm{~h}$, were incubated with gradients of PTX concentrations (5-200 $\mathrm{nM}$ ) for another $48 \mathrm{~h}$ prior to measuring cell viability. EB1 was effectively depleted $(90 \pm 6 \%)$ in all three breast cancer cell lines during this period (Fig. 2A). The ability of PTX to inhibit cell viability increased significantly in the EB1 knockdown (EB1-KD) cells compared with the control cells. We observed that the $\mathrm{IC}_{50}$ of PTX in all three breast cancer cell lines were significantly reduced (Fig. 2B). The $\mathrm{IC}_{50}$ values for the MCF-7, MDA MB-231 and T47D control cells were 38,28 and $59 \mathrm{nM}$, respectively, and the $\mathrm{IC}_{50}$ values for the EB1-KD MCF-7, MDA MB-231 and T47D cells were 23,11 and $43 \mathrm{nM}$, respectively. These results indicate a 40,60 and $28 \%$ reduction in the $\mathrm{IC}_{50}$ in the EB1-KD MCF-7, MDA MB-231 and T47D cells, respectively, compared with 

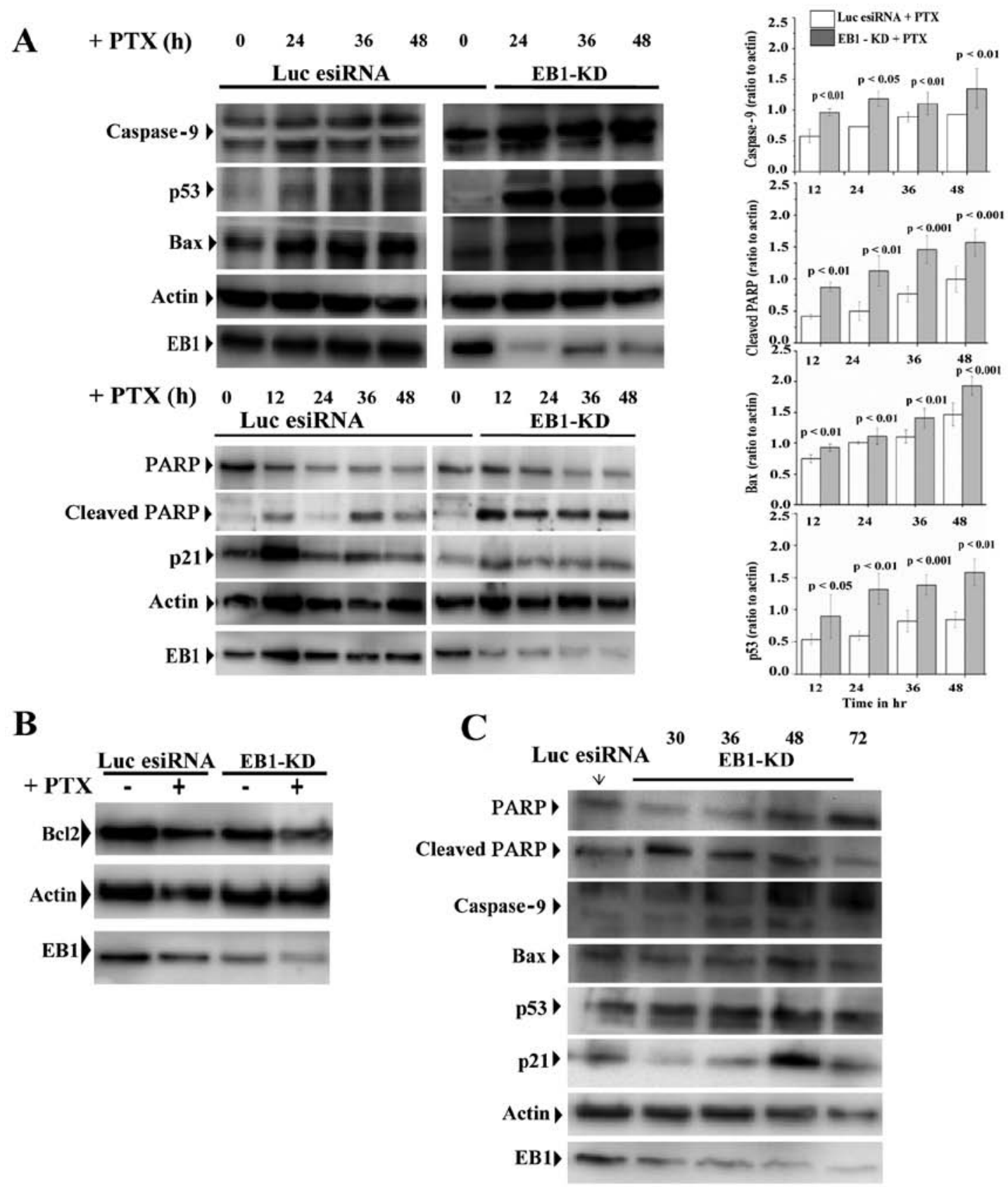

Figure 4. EB1 knockdown (EB1-KD) stimulates activation of p53 and its downstream apoptosis regulators in the paclitaxel (PTX)-treated MCF-7 cells. (A) Immunoblot of MCF-7 cell extracts after luciferase or EB1 esiRNA (siRNA pools) $(24 \mathrm{~h})$ treatment followed by the treatment with PTX (10 $\mathrm{nM}$ ) during the time periods as specified. The levels of cleaved poly(ADP-ribose) polymerase (PARP), caspase-9, p53, Bax, and p21 in the luciferase esiRNA-treated and EB1-KD cells are shown. $\beta$-actin was probed as control. The bar graphs show the densitometric quantification of caspase-9, Bax, cleaved PARP and p53 expression as compared to actin upon PTX treatment during the specified time periods in EB1-KD vs. control luciferase esiRNA-treated cells. Data [mean \pm standard error (SE)] presented are the mean intensity $/ \mathrm{mm}^{2}$ based on three independent experiments. P-values were determined by Student's t-test. (B) Immunoblot showing the levels of Bcl2 in luciferase esiRNA and EB1-KD MCF-7 cells in the presence or absence of PTX (10 nM). (C) Immunoblot of cleaved PARP, caspase-9, p53, Bax, and p21 in MCF-7 cell extracts after EB1 esiRNA treatments for specified time periods. No PTX was added to these cells.

the control cells. EB1-KD alone, in the absence of PTX, did not significantly inhibit cell viability. After $72 \mathrm{~h}$ of EB1 depletion, the percentage of viable cells was reduced only by $17 \%$ (Fig. 2C). Additionally, we also examined the effect of EB1-KD on cytotoxic effects of VIN and the microtubule unrelated drug cisplatin in MCF-7 cells. EB1-KD did not have any effect on either VIN- or cisplatin-induced effects on cell viability in MCF-7 cells (data not shown). We also found that EB1-KD did not significantly enhance PTX sensitivity in the control MCF-10 A and HEK-293 cells (data not shown), indicating that the effect was specific to the breast cancer cells.
EBI depletion sensitizes breast cancer cells to PTX-induced apoptosis via activation of p53 and its downstream apoptosis regulators. Next, we investigated the effect of EB1 depletion on PTX-induced apoptosis in the breast cancer cell lines. After a 24-h esiRNA transfection, the EB1-KD and control cells were treated with a low dose of PTX $\left(10 \mathrm{nM}, \sim 1 / 4\right.$ th of $\mathrm{IC}_{50}$ of PTX in control MCF-7 cells) for the next $48 \mathrm{~h}$ prior to measuring apoptosis using the Annexin $\mathrm{V}$ assay. In all three breast cancer cell lines, there was a significant amount of apoptosis induced in the EB1-depleted cells under PTX treatment (Fig. 3A). While the PTX treatment in the control MCF-7, MDA MB-231 
and T47D cells induced apoptosis in 21,18 and $14 \%$ cells respectively, PTX treatment in the EB1-KD MCF-7, MDA MB-231 and T47D cells induced apoptosis in 30, 30 and 22\% cells, respectively (Fig. 3B). These results were equivalent to a 1.4-, 1.6- and 1.5-fold increase in apoptosis in the MCF-7, MDA MB-231 and T47D cells, respectively. The total cell death increased from 26, 26 and 16\% in the PTX-treated control MCF-7, MDA MB-231 and T47D cells, respectively, to 43,37 and $31 \%$ in the PTX-treated EB1-KD MCF-7, MDA MB-231 and T47D cells, respectively (Fig. 3A), as described in Materials and methods. Furthermore, EB1-KD alone, in the absence of PTX, did not significantly induce apoptosis in any of the three cell lines as compared with control cells not treated with PTX (Fig. 3A and B). These results were confirmed by the Annexin $\mathrm{V}$ and PI immunofluorescence staining results (Fig. 3C).

To elucidate the molecular mechanism underlying apoptosis induced in cells depleted of EB1 and treated with PTX, we analyzed the expression patterns of various apoptosis-associated proteins. The PTX-treated EB1-KD MCF-7 cells demonstrated a time-dependent increase in the caspase-9 expression level and poly(ADP-ribose) polymerase (PARP) cleavage compared with the PTX-treated control cells (Fig. 4A). In addition, the p53 and Bax expression levels were remarkably higher (Fig. 4A), and the $\mathrm{Bcl} 2$ expression level was reduced in the PTX-treated EB1 deficient cells compared with the PTX-treated control cells (Fig. 4B). The p21 expression level, however, appeared similar under both of these conditions (Fig. 4A). Furthermore, there was no significant change in the expression levels of p53, Bax, caspase-9 and PARP in the control EB1-KD cells in the absence of PTX, but the level of p21 was slightly increased in these cells (Fig. 4C).

EB1 depletion induced nuclear accumulation of p53 and increased p53 association with cellular microtubules in PTX-treated MCF-7 cells. Next, we examined the cellular localization of p53 in EB1-KD vs. control cells. Consistent with the increase in p53 expression, the amount of p53 that accumulated in the nucleus was significantly higher in the PTX-treated EB1-KD MCF-7 cells (Fig. 5A). Furthermore, we also observed an increase in the number of multinucleated cells in PTX-treated EB1-KD cells. Approximately 56\% interphase cells were multinucleated, containing two or more nuclei (bar graph, Fig. 5A). Multinucleated cells were also observed in the PTX-treated control cells; however, they were less abundant (31\%). The majority of the multinucleated cells in EB1-KD condition demonstrated a higher accumulation of p53 in their nuclei, whereas the PTX-treated control cells did not demonstrate a higher nuclear accumulation of p53 (bar graph, Fig. 5A).

Next, we investigated whether the association between p53 and the cellular microtubules was altered in the PTX-treated EB1-KD cells. The cellular microtubules were assembled in microtubule-stabilizing buffer and then centrifuged. Finally, the amount of p53 associated with the microtubules was determined using a biochemical analysis, as described in Materials and methods. As expected and consistent with previous studies (51), the PTX-treated control cells demonstrated a moderate increase in the amount of p53 associated with microtubules compared with the cells not treated with
PTX (Fig. 5B). However, when compared with PTX-treated EB1-KD cells, we observed a robust increase ( 3 -fold) in the amount of p53 associated with the cellular microtubules in the EB1-KD cells (Fig. 5B). Unlike the PTX-treated cells, the EB1-KD control cells did not exhibit any noticeable increase in the amount of p53 associated with the microtubules (Fig. 5B). Consistent with the biochemical analysis results, the immunofluorescence images also showed an increase in the amount of p53 localized to the microtubules in the EB1-depleted PTX-treated cells compared with the PTX-treated control and EB1-depleted control cells (Fig. 5C). The co-localization of p53 and the microtubules was evident from the increase in co-staining (yellow) of $\alpha$-tubulin and p53 on microtubules in the merged images (enlarged images, Fig. 5C).

EB1 depletion induced formation of multiple spindle foci in PTX-treated mitotic MCF-7 cells. We investigated the effect of EB1 depletion on the effects of PTX in mitotic cells. First, we determined how the EB1-KD expression affects the levels of the spindle assembly checkpoint (SAC) proteins in MCF-7 cells. There was a higher BubR1 level in the control EB1-KD cells, which was stable and persistent, even after $72 \mathrm{~h}$ of esiRNA treatment (Fig. 6A). A similar change was observed in the Mad2 expression level (Fig. 6A). In contrast, the EB1-KD and control cells demonstrated time-dependent decreases in the BubR1 expression level, albeit at different rates, when treated with PTX (Fig. 6B). While the BubR1 level quickly decreased soon after $12 \mathrm{~h}$ of PTX treatment in the control cells, the rate of BubR1 loss was relatively slower in the EB1-KD cells (Fig. 6B).

Next, we examined the cellular phenotypes induced under these different conditions. MCF-7 cells were immunostained to visualize the chromosomes and spindle microtubules. EB1 depletion alone induced chromosome congressional defects in the metaphase cells (Fig. 6C). The chromosomes appeared to be unorganized and poorly aligned along the metaphase plate. Although the spindle poles appeared to be intact, their positions along the spindle pole axis were disrupted. In the majority of these cells, the poles were displaced from the axis, which resulted in a loss of spindle symmetry. These findings are consistent with previous findings in other cell lines $(33,34)$. We then investigated whether PTX treatment in the EB1-KD cells intensifies the EB1 depletion-induced mitotic defects. PTX treatment in the EB1-KD cells induced multiple spindle foci formation with severe defects in the spindle organization and chromosome congression (Fig. 6C). The chromosomes appeared to be scattered around the spindle foci. The bipolar arrangement of the spindle microtubules was lost. The spindles appeared to be unusually long and curvy (Fig. 6C). About $60 \%$ mitotic cells had multiple spindle foci in the EB1 deficient PTX-treated condition (Fig. 6D). There was a strong correlation between these defects and the level of EB1 depletion in the cells. In contrast to the phenotypes observed in the EB1-depleted cells, the PTX-treated control MCF-7 cells appeared to be predominantly bipolar (Fig. 6C).

EB1 depletion potentiates PTX-induced microtubule stabilization and stabilizes PTX localization in MCF-7 cells. To investigate whether EB1-KD affects the ability of PTX to induce microtubule stabilization in cells, we assessed the 

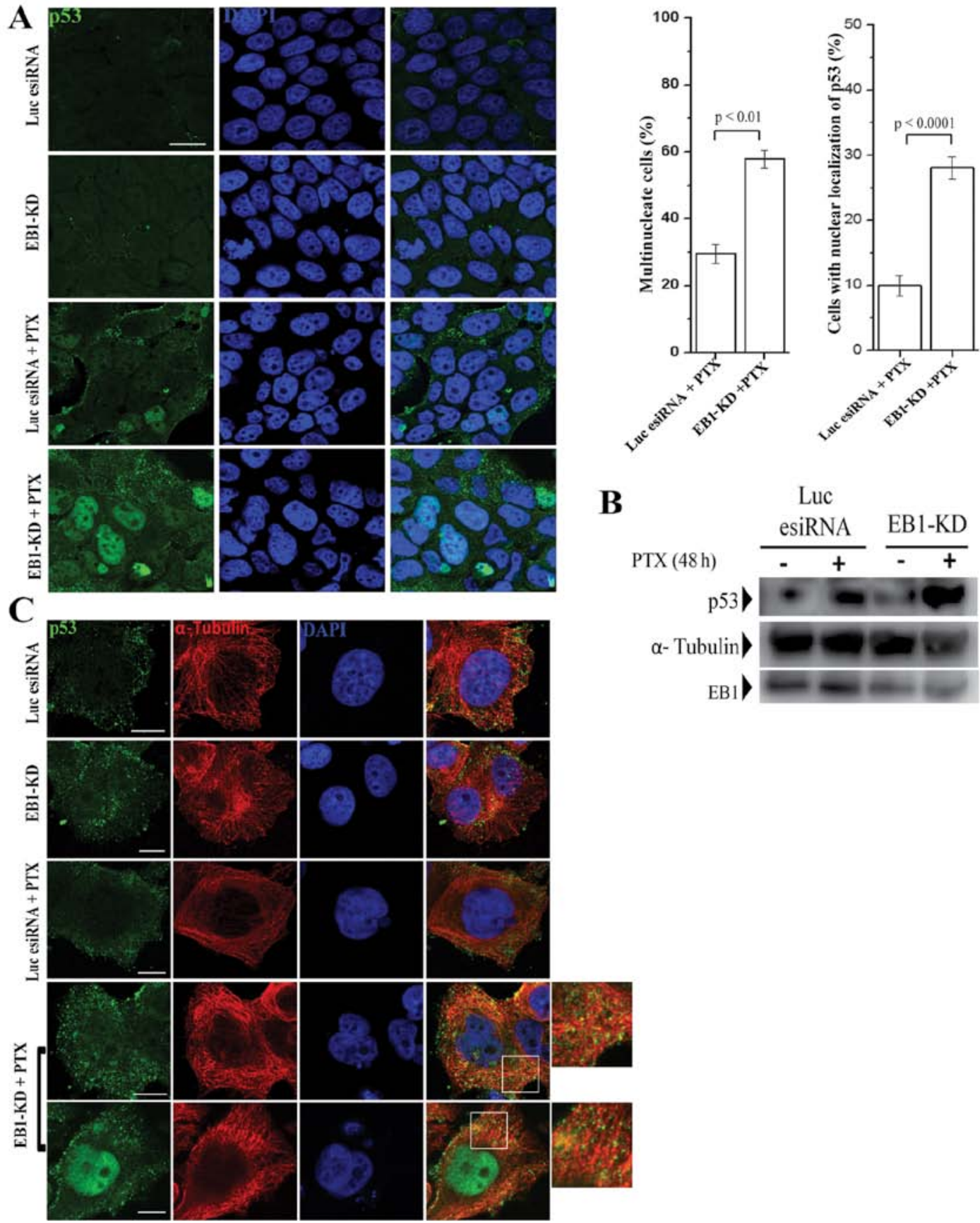

Figure 5. EB1 knockdown (EB1-KD) induces nuclear accumulation of p53 and increases association of p53 onto cellular microtubules in the paclitaxel (PTX)-treated MCF-7 cells. (A) Immunolocalization of p53 in the control, control treated with PTX (10 nM), EB1-KD alone, and EB1-KD MCF-7 cells treated with PTX $(10 \mathrm{nM})$. p53 (green) and DNA (blue, DAPI) was shown. Scale bar, $10 \mu \mathrm{m}$. Bar graphs for the percentages of multinucleated cells and cells with nuclear accumulation of p53 in PTX control cells vs. PTX-treated EB1-KD cells are shown. P-values were determined by Student's t-test. About 500 cells were counted in each case. (B) EB1-KD and luciferase esiRNA-treated MCF-7 cells in the presence (48 h) or absence of PTX (10 nM) were lysed, subjected to microtubule pull-down assay, as described in Materials and methods and analysed by western blot analysis to assess the amount of p53 associated with microtubules. Mouse monoclonal antibodies against $\alpha$-tubulin, p53 and EB1 were used for immunoblot. (C) Immunofluorescence images of p53 (green) localized onto the microtubules (red) in EB1-KD vs. control luciferase esiRNA-treated cells in the presence $(48 \mathrm{~h})$ or absence of PTX (10 nM). Mouse monoclonal p53 (green) and rat $\alpha$-tubulin (red) antibodies were used for immunostaining. Nuclei were stained with DAPI. Scale bar, $10 \mu \mathrm{m}$. Box areas are shown by enlarged images.

stabilization of microtubules in PTX-treated control and EB1-KD cells. We used microtubule bundling (lateral association of microtubules) in an immunofluorescence assay to determine the PTX-induced stabilization of microtubules because microtubule bundle formation is the result of PTX-mediated microtubule polymer stabilization and therefore, represents the cellular activity of taxanes (15) (shown by arrows, Fig. 7A). Consistent with the previous studies (15), we observed formation of microtubule bundles in MCF-7 cells upon PTX treatment (Fig. 7A). However, the relative size and the number density of the bundles were significantly increased in the EB1-KD cells compared with the PTX-treated control cells (Fig. 7A). Based on an analysis of a large population of cells, it was found that the average microtubule intensity within 
A

B
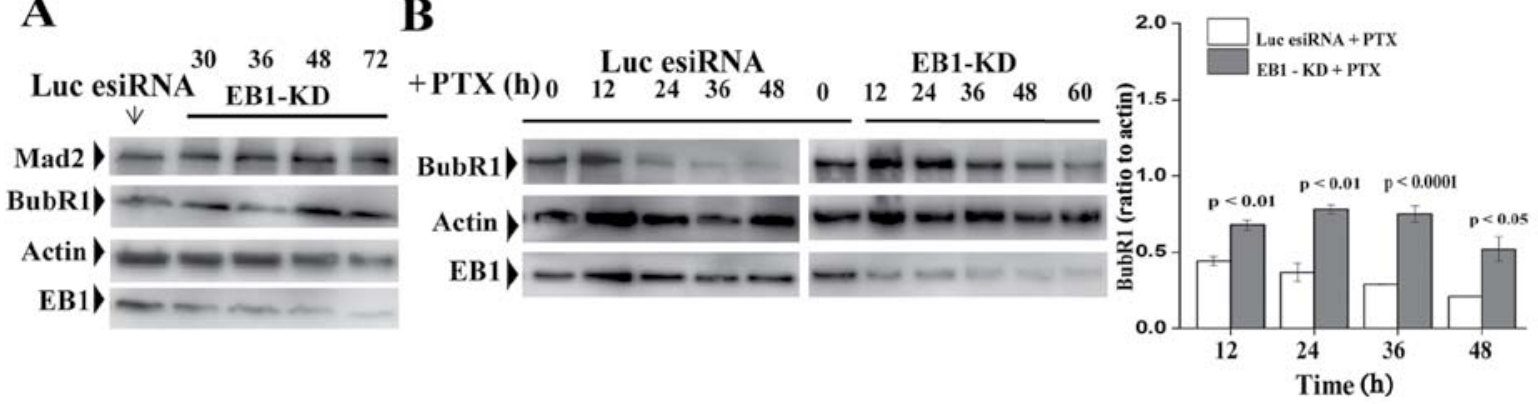

C
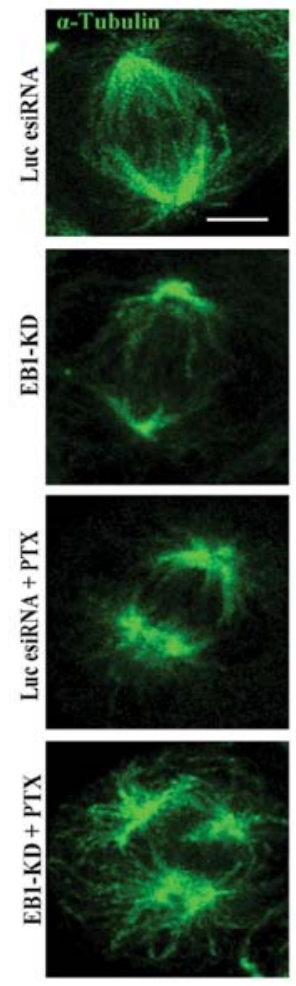
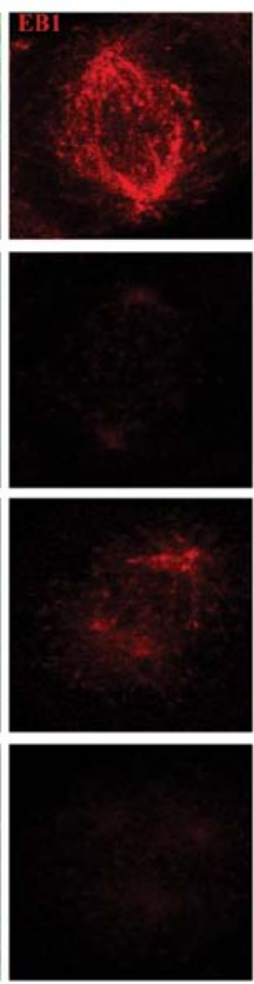
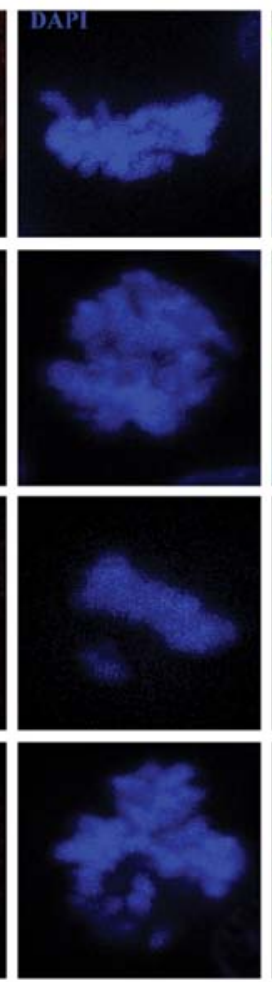

D
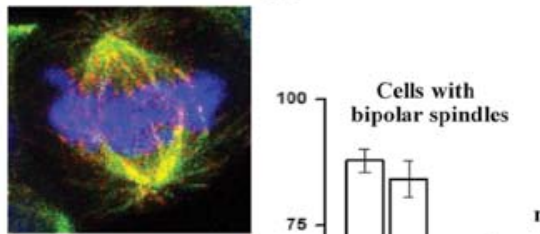

Cells with multiple spindle foci
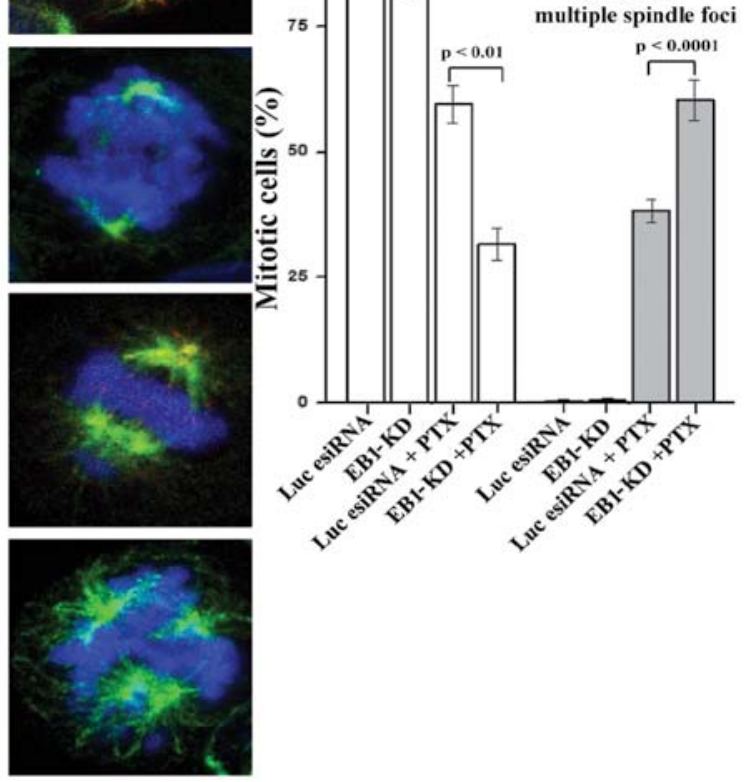

Figure 6. EB1 knockdown (EB1-KD) induces formation of multiple spindle foci in the paclitaxel (PTX)-treated mitotic MCF-7 cells. (A) Immunoblot showing the expression of Mad2 and BubR1 in MCF-7 cells treated with EB1 esiRNA for the specified time periods. (B) Immunoblot showing the expression of BubR1 in control vs. EB1-KD MCF-7 cells after treatment with PTX (10 nM) for the specified time periods. Plot shows the densitometric analysis of BubR1 at different time periods [three independent experiments, mean \pm standard error (SE)]. P-values were determined by Student's t-test. (C) Confocal micrographs of cells showing the microtubules (green), EB1 (red) and DNA (blue) in EB1-KD vs. control MCF-7 cells after PTX treatment (48 h). Scale bar, $10 \mu \mathrm{m}$. The cells were stained with mouse monoclonal anti- $\alpha$-tubulin and rabbit polyclonal anti-EB1. DNA was stained with DAPI. (D) Percentages of cells with bipolar spindles and multiple spindle foci under similar conditions as of (C) are plotted. Data are mean \pm SE (three independent experiments). About 100-125 mitotic cells were counted for each experiment.

the bundles was $40 \%$ higher in the PTX-treated EB1-KD cells compared with the PTX-treated control cells (Fig. 7B). We also found that the average intensity of microtubules that are not associated with the bundles was similar in the control vs. the EB1-KD cells (not shown). To determine if this increase in microtubule bundling is the result of an increase in PTX localization in cells, we treated EB1-KD and control esiRNA-treated cells with fluorescent Ore-PTX and then determined the intracellular level of fluorescent PTX in the MCF-7 cells by live imaging. The level of intracellular fluorescent PTX was visibly higher in the PTX-treated EB1-KD cells compared with the PTX-treated control cells (Fig. 7C).

EB1 inhibited PTX-induced microtubule polymerization and PTX binding on microtubules. Next, we investigated whether EB1 regulates PTX-induced microtubule polymerization. PTX-induced microtubule polymerization was carried out in vitro by adding $0.1 \mu \mathrm{M}$ PTX to purified tubulin. The turbidity curve indicates that $0.1 \mu \mathrm{M}$ PTX was very efficient in inducing microtubule polymerization (square, Fig. 8A). Polymerization was attenuated when PTX was added to the pre-incubated mixture of tubulin and EB1. It was reduced by $\sim 40 \%$ with only $0.1 \mu \mathrm{M}$ EB1 $(1: 1$ molar ratio of EB1 and PTX) (lower triangle, Fig. 8A). A 2-fold molar excess of EB1 over PTX further suppressed the polymerization by $\sim 60 \%$ (circle, Fig. $8 \mathrm{~A}$ ). By using an unrelated histidine-tagged protein, we also confirmed that the inhibition of polymerization was not due to any non-specific effect of the 6-His tag attached to EB1 (data not shown). The inhibition of polymerization by EB1 was further confirmed 
A

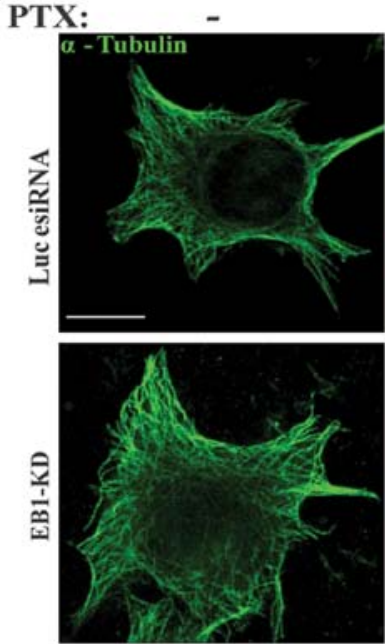

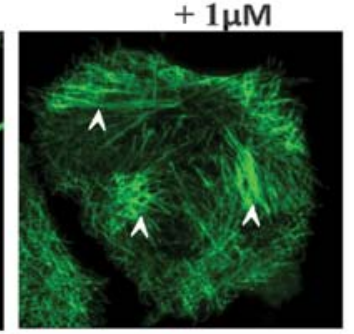

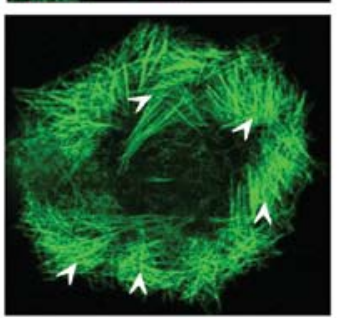

B

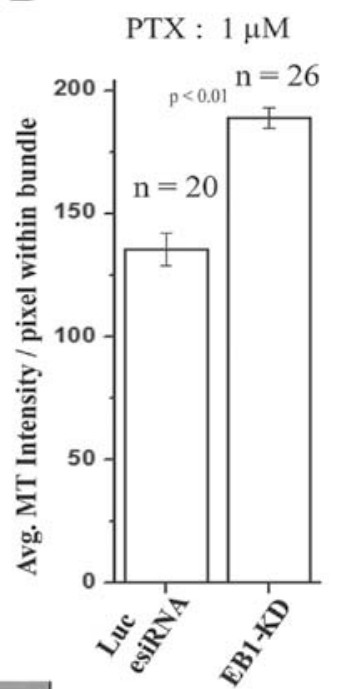

C
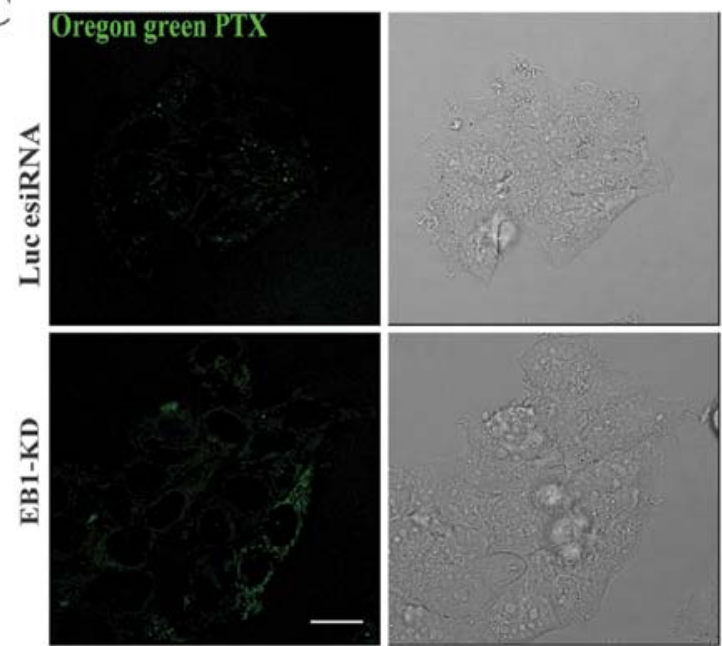

Figure 7. EB1 depletion enhances paclitaxel (PTX)-induced cellular microtubule bundling. (A) Immunofluorescence images showing the bundling of microtubules after treatment with $1 \mu \mathrm{M}$ PTX for $24 \mathrm{~h}$ in EB1 knockdown (EB1-KD) vs. luciferase esiRNA-treated MCF-7 cells. Scale bar, $10 \mu \mathrm{m}$. Microtubules were stained with mouse monoclonal $\alpha$-tubulin antibody. (B) Average microtubule intensities per pixel within the microtubule bundles in the control vs. EB1-KD cells upon treatment with $1 \mu \mathrm{M}$ PTX for $24 \mathrm{~h}$ were plotted. $\mathrm{n}$ refers to the number of cells analysed. (C) Images showing the localization of Oregon green 488-labeled PTX (Ore-PTX) (10 nM) in the control vs. EB1-KD cells. MCF-7 cells treated with EB1 esiRNA or luciferase esiRNA for $24 \mathrm{~h}$ were incubated with Ore-PTX $(10 \mathrm{nM})$ for the next $24 \mathrm{~h}$ prior to capture the images of the live cells. Scale bar, $10 \mu \mathrm{m}$.

by an SDS-PAGE analysis of the PTX-assembled microtubules after separating the polymerized proteins from the unpolymerized fractions through glycerol cushion followed by centrifugation (inset, Fig. 8A), as described in Materials and methods. The SDS-PAGE data also showed that the association between EB1 and the microtubules increased in a concentration-dependent manner (Fig. 8A). We also found that EB1 did not inhibit microtubule polymerization when the microtubules were polymerized from tubulin using DMSO as inducer (not shown), indicating that the inhibitory effect of EB1 is very much specific to the PTX-induced microtubule polymerization.

We then investigated whether EB1 affects PTX binding on microtubules. For this, we performed a quantitative fluorescence-based assay. The fluorescent Ore-PTX was allowed to bind to pre-polymerized steady-state microtubules in vitro in the absence or presence of increasing concentrations of EB1. The amount of PTX bound to the microtubules was determined by measuring the fluorescence intensity of the
Ore-PTX associated with the microtubules, as described in Materials and methods. The Ore-PTX fluorescence in the microtubule solutions was reduced in the presence of EB1 indicating that EB1 inhibited the association between Ore-PTX and the microtubules in a dose-dependent manner (Fig. 8B). At $100 \mathrm{nM}$ EB1 which corresponds to the molar ratio of PTX:EB1 as 1:5, the Ore-PTX binding was inhibited by $\sim 30 \%$. The inhibition was further increased to $\sim 40 \%$ at $200 \mathrm{nM}$ EB1 (Fig. $8 \mathrm{~B}$ and C). Increase of EB1 $>200 \mathrm{nM}$ did not show any additional increase in the inhibition of PTX binding beyond $40 \%$. We also confirmed by SDS-PAGE analysis that EB1 did not significantly alter the total microtubule polymer mass in the range of concentrations (20-200 $\mathrm{nM}$ ) used in the PTX-binding experiment (inset, Fig. 8B) (28). This result confirms that the reduction of PTX binding to the microtubules in the presence of EB1 was not due to any decrease in the total microtubule polymer mass, but rather it was due to inhibition of PTX binding by EB1 to the microtubules. Altogether, these results 

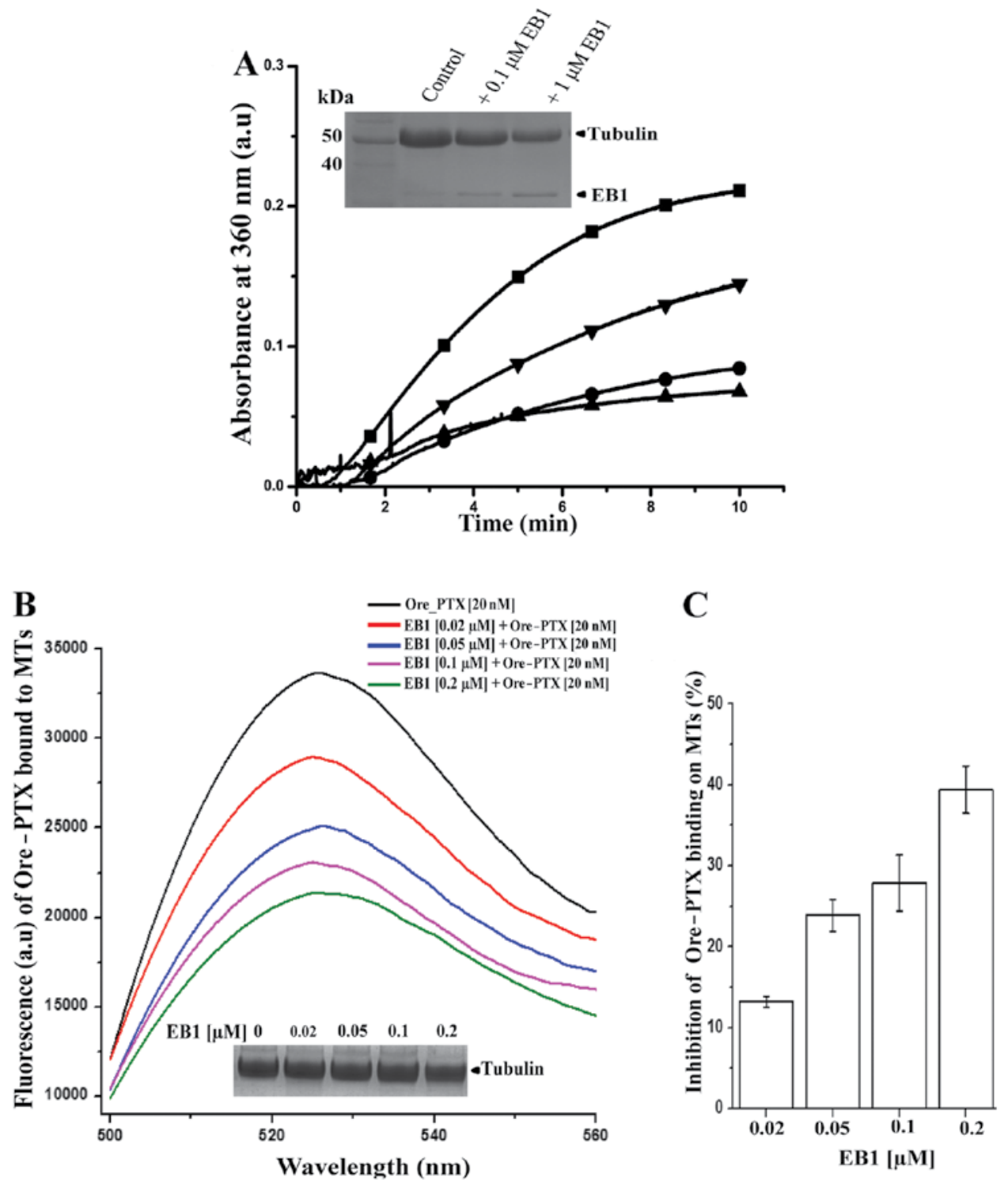

Figure 8. EB1 inhibits paclitaxel (PTX)-induced microtubule polymerization and PTX binding on microtubules. (A) Tubulin (15 $\mu \mathrm{M})$ was pre-incubated with $0 \mu \mathrm{M}(\mathbf{\bullet}), 0.1 \mu \mathrm{M}(\mathbf{v}), 1 \mu \mathrm{M}(\bullet)$ and $5 \mu \mathrm{M}(\mathbf{\Delta})$ human recombinant EB1, respectively and then polymerized with $0.1 \mu \mathrm{M}$ PTX. Microtubule polymerization was monitored by measuring the turbidity at $360 \mathrm{~nm}$ with time. Inset: after completion of polymerization, the microtubules were pelleted, re-dissolved in cold buffer, and were run through 12\% SDS-PAGE followed by staining with Coomassie blue. (B) Oregon green 488-labeled PTX (Ore-PTX) (20 nM) was added either to the polymerized control microtubules or to the microtubules pre-incubated with EB1 (ranging from 20 to $200 \mathrm{nM}$ ), incubated for $15 \mathrm{~min}$ at $35^{\circ} \mathrm{C}$ prior to centrifugation through 15\% glycerol cushion, as described in Materials and methods. The fluorescence of Ore-PTX bound to the microtubules was recorded at an excitation of $488 \mathrm{~nm}$. The inset shows 10\% SDS-PAGE followed by Coomassie blue staining of the pelleted microtubules at different concentrations of EB1. (C) The bar graph shows the percent inhibition of Ore-PTX binding on microtubules in the presence of EB1. Percent inhibition for the control in the absence of EB1 was considered as zero. The maximum fluorescence value in each curve shown in (B) was used for the calculation of percent inhibition.

indicate that EB1 inhibits PTX-mediated microtubule polymerization by preventing PTX binding to the microtubules.

\section{Discussion}

EB1 is a major +TIP and has previously been shown to promote proliferation of breast cancer cells $(22,38)$. However, its effects on the sensitivity of breast cancer cells to microtubule-targeted drugs have not been clearly understood. In the present study, we demonstrate that EB1 plays an important role in regulating the sensitivity of breast cancer cells to microtubule-stabilizing drug, PTX. We show that PTX sensitivity correlates negatively with the EB1 expression level in breast cancer cell lines (Fig. 1). The EB1-KD increases PTX sensitivity in breast cancer cells by stimulating PTX-induced apoptosis and inhibition of cell viability (Figs. 2-4). Our findings support a mechanism in which EB1 downregulates PTX sensitivity by impairing PTX-induced stabilization of microtubule polymerization and inhibiting PTX binding to the microtubules (Figs. 6-8). During the preparation of this manuscript, we found a related report published by Luo et al (52), in which they investigated the role of EB1 on PTX sensitivity in breast cancer cells. However, it did not provide a clear conclusion due to a number of reasons. First, EB1 depletion was not significant in the study. Furthermore, GFP-fused EB1 was used to examine the effect of EB1 overexpression on PTX sensitivity. Fusion of GFP either to the N- or the C-terminus of EB1 has previously been shown to inhibit EB1's ability to bind to the microtubules 
and to other +TIPs (53). The results of Luo et al (52) also could not clearly address the effect of EB1 on PTX-induced microtubule polymerization as the EB1 protein used in their assay was tagged with glutathione S-transferase (GST). Since GST is a bulky molecule and it itself exerts an effect on microtubule polymerization (52), the results could not clearly describe the exclusive role of EB1 in PTX-induced microtubule polymerization. In this study, we used esiRNAs, which ensured $>90 \%$ suppression of EB1 expression in all the breast cancer cell lines used in this study (Fig. 2A). In the biochemical assays, we used purified recombinant human EB1, which clearly describes the exclusive effect of EB1 on PTX-induced microtubule polymerization (Fig. 8).

It has been previously reported that an increase in the nuclear translocation of p53 in cancer cells occurs in response to treatment with microtubule-targeting drugs, including PTX $(51,56)$. It is generally accepted that the drug-induced stabilization of microtubules is the primary mechanism responsible for the increase in the p53 association with microtubules and its nuclear export $(51,54,55)$. Consistently, we found that the association between p53 and cellular microtubules increased in response to PTX treatment in the control cells (51) (Fig. 5B and C). However, the association between p53 and cellular microtubules was further increased in the PTX-treated EB1-KD cells (Fig. 5B and C). The increased p53-microtubule association in PTX-treated EB1-KD cells could be the result of an increase in the stabilization of microtubules in the PTX-treated EB1-KD cells compared with the PTX-treated control cells. In support of this mechanism, we showed that microtubule bundling was greater in the PTX-treated EB1 deficient interphase cells compared with the PTX-treated control interphase cells (Fig. 7A). Consistently, we also observed an increase in the abundance of multiple spindle foci with abnormally long spindles in the PTX-treated EB1-KD mitotic cells (Fig. 6D). We also found that the level of intracellular PTX was higher in the EB1 deficient cells, which suggests that the association between PTX and the cellular microtubules is increased in the absence of EB1 (Fig. 7B). Altogether, these results support a mechanism in which EB1 inhibits the microtubule-stabilizing function of PTX. The results also support the previously proposed hypothesis that microtubule stabilization and p53 activation are closely linked $(51,56)$.

EB1 mediates several key interactions that are essential for stabilizing spindle-chromosome attachment and activation of the SAC. For example, it has been shown that the disruption of its interaction with the plus-end protein TIP150 activates the SAC in HeLa cells (35). Consistently, we found that the EB1-KD resulted in a prolonged and stable accumulation of BubR1 and Mad2 in the control cells (Fig. 6A). It suggests that the EB1-deficient control cells undergo a stable mitotic arrest. On the contrary, EB1-deficient cells treated with PTX exhibited a time-dependent decrease in the BubR1 level, which indicates that the SAC became less effective or was suppressed by PTX treatment (Fig. 6B). It has been shown previously that mitotic cells with weak SAC activation may undergo apoptosis through either of these mechanisms: apoptosis may be triggered at the mitotically arrested stage, or the cells may exit mitosis as viable cells but then die at a multinucleated G1-stage (57). Our findings that PTX treatment increased apoptosis (Fig. 4A) and induced multinucleation with increased nuclear accumulation of p53 in the EB1-KD cells (Fig. 5A), suggest that apoptosis was triggered at the multinucleated stage after exiting mitosis rather than at the mitosis. We also found that the loss of BubR1 occurred relatively more rapidly in the PTX-treated control cells than in the PTX-treated EB1-KD cells (Fig. 6B). This indicates that the SAC activation was relatively weaker and transient in the PTX-treated control cells than the PTX-treated EB1-KD cells. As the PTX-treated control cells did not exhibit significant apoptosis like the PTX-treated EB1-KD cells (Fig. 3), a likely possibility is that these cells proceeded to the next round of division. In support of this possibility, we found that PTX-treated control cells displayed higher cell viability (higher $\mathrm{IC}_{50}$ of PTX) as compared with the PTX-treated EB1-KD cells (Fig. 2).

Recent high resolution electron microscopy analysis of interaction between the Schizosaccharomyces pombe EB1 homolog Mal3p and microtubules showed that EB1 binds between the microtubule protofilaments at and near the plus-ends $(58,59)$. Combination of in vitro reconstitution and the sub-pixel level fluorescence analysis with human recombinant EB1 further revealed that EB1 binding accelerates the conformational maturation of microtubules at the polymerizing ends (32). Because EB1 is involved in conformational maturation of the ends, it may affect the assembly of protofilaments during PTX-mediated microtubule polymerization. Consistent with this mechanism, we found that PTX-induced microtubule polymerization was inhibited by EB1 (Fig. 8). Although EB1 effectively inhibited microtubule polymerization induced by PTX, it did not inhibit DMSO-induced microtubule polymerization (not shown), or it did not depolymerize the pre-polymerized steady-state microtubules in vitro (Fig. 8B) (28). These findings suggest that EB1 specifically inhibits the action of PTX on the microtubules, presumably by preventing PTX to bind to the tubulin subunits on the microtubules and to induce the assembly of the protofilaments.

How could EB1 being a +TIP inhibit the anti-mitotic action of PTX, which is known to bind all along the microtubule protofilament? It has been demonstrated previously that PTX exerts its anti-mitotic action in cancer cells at a very sub-stoichiometric level, the concentrations at which it does not significantly affect microtubule polymer mass, but suppresses microtubule dynamics very efficiently $(11,12)$. This suggested that the anti-mitotic action of PTX is predominantly attributed to its binding at the microtubule plus-ends rather than its binding along the microtubule surface (6). Thus, the increased accumulation of EB1 on plus-ends of microtubules could specifically inhibit binding of PTX to the ends, but PTX binding along the surface of microtubule may not be affected under such condition. Consistent with this possibility, we observed that EB1 inhibited binding of PTX on the microtubules to a maximum extent of $40 \%$, and the remaining $60 \%$ PTX was still bound to the microtubules (Fig. 8B). The inhibitory effect of EB1 on PTX-induced microtubule polymerization is also in good support with the effects of the EB proteins on the dynamics of PTX-treated microtubules shown by Mohan et al (31) in which they showed that the overall dynamicity of PTX-treated microtubules is increased in the presence of EB proteins in vitro. Specifically, the EB proteins increased the frequencies 
of growth (rescue) and shortening (catastrophe) of the PTX-treated microtubules (31). Similar to these findings, study by Pagano et al, showed that at low PTX concentration, microtubule dynamics is increased instead of suppressed in the presence of EB protein, EB3 (60).

In summary, we show from our cellular and biochemical results that inhibition of EB1 expression sensitizes breast cancer cells to PTX-induced cytotoxicity and apoptosis. The ability of EB1 to inhibit PTX-induced microtubule polymerization and PTX binding to the microtubules suggests that EB1 confers resistance against the microtubule-stabilizing activity of PTX. The results support the hypothesis that EB1 downregulates PTX sensitivity through a mechanism in which it inhibits PTX binding to the microtubules and suppresses PTX-induced stabilization of microtubule polymerization.

\section{Acknowledgements}

We thank S. Murty Srinivasula, IISER-Thiruvananthapuram for critical comments and suggestions, and for providing cell lines. We also thank Stephen Doxsey, UMass Medical (Worcester, MA, USA) for providing pGFP-EB1 plasmid. This study was supported by a CSIR-Govt. of India research grant to T.M.

\section{References}

1. Kamangar F, Dores GM and Anderson WF: Patterns of cancer incidence, mortality, and prevalence across five continents: defining priorities to reduce cancer disparities in different geographical regions of the world. J Clin Oncol 24: 2137-2150, 2006

2. Mamounas EP, Bryant J, Lembersky B, Fehrenbacher L, Sedlacek SM, Fisher B, Wickerham DL, Yothers G, Soran A and Wolmark N: Paclitaxel after doxorubicin and cyclophosphamide as adjuvant chemotherapy for node-positive breast cancer: results from NSABP B-28. J Clin Oncol 23: 3686-3696, 2005.

3. Martin M, Seguí MA, Antón A, Ruiz A, Ramos M, Adrover E, Aranda I, Rodríguez-Lescure A, Grosse R, Calvo L, et al; GEICAM 9805 Investigators: Adjuvant docetaxel for high-risk, node-negative breast cancer. N Engl J Med 363: 2200-2210, 2010.

4. Henderson IC, Berry DA, Demetri GD, Cirrincione CT, Goldstein LJ, Martino S, Ingle JN, Cooper MR, Hayes DF, Tkaczuk KH, et al: Improved outcomes from adding sequential Paclitaxel but not from escalating Doxorubicin dose in an adjuvant chemotherapy regimen for patients with node-positive primary breast cancer. J Clin Oncol 21: 976-983, 2003.

5. McGrogan BT, Gilmartin B, Carney DN and McCann A: Taxanes, microtubules and chemoresistant breast cancer. Biochim Biophys Acta 1785: 96-132, 2008

6. Jordan MA and Wilson L: Microtubules as a target for anticancer drugs. Nat Rev Cancer 4: 253-265, 2004.

7. Manfredi JJ, Parness J and Horwitz SB: Taxol binds to cellular microtubules. J Cell Biol 94: 688-696, 1982.

8. Giannakakou P, Gussio R, Nogales E, Downing KH, Zaharevitz D, Bollbuck B, Poy G, Sackett D, Nicolaou KC and Fojo T: A common pharmacophore for epothilone and taxanes: molecular basis for drug resistance conferred by tubulin mutations in human cancer cells. Proc Natl Acad Sci USA 97: 2904-2909, 2000.

9. Orr GA, Verdier-Pinard P, McDaid H and Horwitz SB: Mechanisms of Taxol resistance related to microtubules. Oncogene 22: 7280-7295, 2003.

10. Kavallaris M, Kuo DY, Burkhart CA, Regl DL, Norris MD, Haber $M$ and Horwitz SB: Taxol-resistant epithelial ovarian tumors are associated with altered expression of specific beta-tubulin isotypes. J Clin Invest 100: 1282-1293, 1997.

11. Derry WB, Wilson L and Jordan MA: Substoichiometric binding of taxol suppresses microtubule dynamics. Biochemistry 34: 2203-2211, 1995
12. Jordan MA, Toso RJ, Thrower D and Wilson L: Mechanism of mitotic block and inhibition of cell proliferation by taxol at low concentrations. Proc Natl Acad Sci USA 90: 9552-9556, 1993.

13. Blagosklonny MV, Robey R, Sheikh MS and Fojo T: Paclitaxel-induced FasL-independent apoptosis and slow (non-apoptotic) cell death. Cancer Biol Ther 1: 113-117, 2002.

14. Ganguly A, Yang H, Pedroza M, Bhattacharya R and Cabral F: Mitotic centromere-associated kinesin (MCAK) mediates paclitaxel resistance. J Biol Chem 286: 36378-36384, 2011.

15. Sung $M$ and Giannakakou P: BRCA1 regulates microtubule dynamics and taxanes-induced apoptotic cell signaling. Oncogene 33: 1418-1428, 2014.

16. Wang H, Liu B, Zhang C, Peng G, Liu M, Li D, Gu F, Chen Q, Dong JT, Fu L and Zhou J: Parkin regulates paclitaxel sensitivity in breast cancer via a microtubule-dependent mechanism. J Pathol 218: 76-85, 2009.

17. Alli E, Bash-Babula J, Yang JM and Hait WN: Effect of stathmin on the sensitivity to antimicrotubule drugs in human breast cancer. Cancer Res 62: 6864-6869, 2002.

18. Sun X, Li D, Yang Y, Ren Y, Li J, Wang Z, Dong B, Liu M and Zhou J: Microtubule-binding protein CLIP-170 is a mediator of paclitaxel sensitivity. J Pathol 226: 666-673, 2012.

19. Lu Q and Luduena RF: Removal of beta III isotype enhances taxol induced microtubule assembly. Cell Struct Funct 18: 173-182, 1993.

20. Kamath K, Wilson L, Cabral F and Jordan MA: Beta-tubulin induces paclitaxel resistance in association with reduced effects on microtubule dynamic instability. J Biol Chem 280: 12902-12907, 2005.

21. Akhmanova A and Steinmetz MO: Tracking the ends: a dynamic protein network controls the fate of microtubule tips. Nat Rev Mol Cell Biol 9: 309-322, 2008.

22. Honnappa S, Okhrimenko O, Jaussi R, Jawhari H, Jelesarov I, Winkler FK and Steinmetz MO: Key interaction modes of dynamic +TIP networks. Mol Cell 23: 663-671, 2006.

23. Komarova Y, Lansbergen G, Galjart N, Grosveld F, Borisy GG and Akhmanova A: EB1 and EB3 control CLIP dissociation from the ends of growing microtubules. Mol Biol Cell 16: 5334-5345, 2005

24. Askham JM, Vaughan KT, Goodson HV and Morrison EE: Evidence that an interaction between EB1 and p150(Glued) is required for the formation and maintenance of a radial microtubule array anchored at the centrosome. Mol Biol Cell 13: 3627-3645, 2002.

25. Dixit R, Barnett B, Lazarus JE, Tokito M, Goldman YE and Holzbaur EL: Microtubule plus-end tracking by CLIP-170 requires EB1. Proc Natl Acad Sci USA 106: 492-497, 2009.

26. Su LK and Qi Y: Characterization of human MAPRE genes and their proteins. Genomics 71: 142-149, 2001.

27. Tirnauer JS, Grego S, Salmon ED and Mitchison TJ: EB1-microtubule interactions in Xenopus egg extracts: role of EB1 in microtubule stabilization and mechanisms of targeting to microtubules. Mol Biol Cell 13: 3614-3626, 2002.

28. Manna T, Honnappa S, Steinmetz MO and Wilson L: Suppression of microtubule dynamic instability by the +TIP protein EB1 and its modulation by the CAP-Gly domain of p150glued. Biochemistry 47: 779-786, 2008.

29. Vitre B, Coquelle FM, Heichette C, Garnier C, Chrétien D and Arnal I: EB1 regulates microtubule dynamics and tubulin sheet closure in vitro. Nat Cell Biol 10: 415-421, 2008

30. Komarova Y, De Groot CO, Grigoriev I, Gouveia SM, Munteanu EL, Schober JM, Honnappa S, Buey RM, Hoogenraad CC, Dogterom M, et al: Mammalian end binding proteins control persistent microtubule growth. J Cell Biol 184: 691-706, 2009.

31. Mohan R, Katrukha EA, Doodhi H, Smal I, Meijering E, Kapitein LC, Steinmetz MO and Akhmanova A: End-binding proteins sensitize microtubules to the action of microtubule-targeting agents. Proc Natl Acad Sci USA 110: 8900-8905, 2013.

32. Maurer SP, Cade NI, Bohner G, Gustafsson N, Boutant E and Surrey T: EB1 accelerates two conformational transitions important for microtubule maturation and dynamics. Curr Biol 24: 372-384, 2014.

33. Draviam VM, Shapiro I, Aldridge B and Sorger PK: Misorientation and reduced stretching of aligned sister kinetochores promote chromosome missegregation in EB1- or APC-depleted cells. EMBO J 25: 2814-2827, 2006.

34. Brüning-Richardson A, Langford KJ, Ruane P,Lee T, Askham JM and Morrison EE: EB1 is required for spindle symmetry in mammalian mitosis. PLoS One 6: e28884, 2011. 
35. Ward T, Wang M, Liu X, Wang Z, Xia P, Chu Y, Wang X, Liu L, Jiang K, Yu H, et al: Regulation of a dynamic interaction between two microtubule-binding proteins, EB1 and TIP150, by the mitotic p300/CBP-associated factor (PCAF) orchestrates kinetochore microtubule plasticity and chromosome stability during mitosis. J Biol Chem 288: 15771-15785, 2013.

36. Green RA, Wollman R and Kaplan KB: APC and EB1 function together in mitosis to regulate spindle dynamics and chromosome alignment. Mol Biol Cell 16: 4609-4622, 2005.

37. Sun L, Gao J, Dong X, Liu M, Li D, Shi X, Dong J, Lu X, Liu C and Zhou J: EB1 promotes Aurora-B kinase activity through blocking its inactivation by protein phosphatase $2 \mathrm{~A}$. Proc Natl Acad Sci USA 105: 7153-7158, 2008.

38. Dong X, Liu F, Sun L, Liu M, Li D, Su D, Zhu Z, Dong JT, Fu L and Zhou J: Oncogenic function of microtubule end-binding protein 1 in breast cancer. J Pathol 220: 361-369, 2010.

39. Jaïs P, Sabourin JC, Bombled J, Rougier P, Lasser P, Duvillard P, Bénard $\mathrm{J}$ and Bressac-de Paillerets B: Absence of somatic alterations of the EB1 gene adenomatous polyposis coli-associated protein in human sporadic colorectal cancers. Br J Cancer 78: 1356-1360, 1998.

40. Nishigaki R, Osaki M, Hiratsuka M, Toda T, Murakami K, Jeang KT, Ito $\mathrm{H}$, Inoue $\mathrm{T}$ and Oshimura M: Proteomic identification of differentially-expressed genes in human gastric carcinomas. Proteomics 5: 3205-3213, 2005.

41. Wang Y, Zhou X, Zhu H, Liu S, Zhou C, Zhang G, Xue L, Lu N, Quan L, Bai J, et al: Overexpression of EB1 in human esophageal squamous cell carcinoma (ESCC) may promote cellular growth by activating beta-catenin/TCF pathway. Oncogene 24 : 6637-6645, 2005.

42. Soule HD, Maloney TM, Wolman SR, Peterson WD Jr, Brenz R, McGrath CM, Russo J, Pauley RJ, Jones RF and Brooks SC: Isolation and characterization of a spontaneously immortalized human breast epithelial cell line, MCF-10. Cancer Res 50: 6075-6086, 1990.

43. Kittler R, Heninger AK, Franke K, Habermann B and Buchholz F: Production of endoribonuclease-prepared short interfering RNAs for gene silencing in mammalian cells. Nat Methods 2: 779-784, 2005

44. Calegari F, Haubensak W, Yang D, Huttner WB and Buchholz F: Tissue-specific RNA interference in post-implantation mouse embryos with endoribonuclease-prepared short interfering RNA. Proc Natl Acad Sci USA 99: 14236-14240, 2002.

45. Manna T, Thrower DA, Honnappa S, Steinmetz MO and Wilson L: Regulation of microtubule dynamic instability in vitro by differentially phosphorylated stathmin. J Biol Chem 284: 15640-15649, 2009.

46. Bradford MM: A rapid and sensitive method for the quantitation of microgram quantities of protein utilizing the principle of protein-dye binding. Anal Biochem 72: 248-254, 1976.

47. Zhang L, Lau YK, Xia W, Hortobagyi GN and Hung MC: Tyrosine kinase inhibitor emodin suppresses growth of HER-2/neu-overexpressing breast cancer cells in athylic mice and sensitizes these cells to the inhibitory effects of paclitaxel. Clin Cancer Res 5: 343-353, 1999.
48. Gireesh KK, Rashid A, Chakraborti S, Panda D and Manna T: CIL-102 binds to tubulin at colchicine binding site and triggers apoptosis in MCF-7 cells by inducing monopolar and multinucleated cells. Biochem Pharmacol 84: 633-645, 2012.

49. Young A, Dictenberg JB, Purohit A, Tuft R and Doxsey SJ: Cytoplasmic dynein-mediated assembly of pericentrin and gamma tubulin onto centrosomes. Mol Biol Cell 11: 2047-2056, 2000.

50. Ciardiello F, Caputo R, Pomatico G, De Laurentiis M, De Placido S, Bianco AR, Tortora G: Resistance to taxanes is induced by c-erbB-2 overexpression in human MCF-10A mammary epithelial cells and is blocked by combined treatment with an antisense oligonucleotide targeting type I protein kinase A. Int J Cancer 85: 710-715, 2000.

51. Giannakakou P, Sackett DL, Ward Y, Webster KR, Blagosklonny MV and Fojo T: p53 is associated with cellular microtubules and is transported to the nucleus by dynein. Nat Cell Biol 2: 709-717, 2000.

52. Luo Y, Li D, Ran J, Yan B, Chen J, Dong X, Liu Z, Liu R, Zhou J and Liu M: End-binding protein 1 stimulates paclitaxel sensitivity in breast cancer by promoting its actions toward microtubule assembly and stability. Protein Cell 5: 469-479, 2014.

53. Skube SB, Chaverri JM and Goodson HV: Effect of GFP tags on the localization of EB1 and EB1 fragments in vivo. Cytoskeleton (Hoboken) 67: 1-12, 2010.

54. Giannakakou P, Nakano M, Nicolaou KC, O'Brate A, Yu J, Blagosklonny MV, Greber UF and Fojo T: Enhanced microtubule-dependent trafficking and p53 nuclear accumulation by suppression of microtubule dynamics. Proc Natl Acad Sci USA 99: 10855-10860, 2002

55. Rathinasamy K and Panda D: Kinetic stabilization of microtubule dynamic instability by benomyl increases the nuclear transport of p53. Biochem Pharmacol 76: 1669-1680, 2008

56. Carney BK, Caruso Silva V and Cassimeris L: The microtubule cytoskeleton is required for a $\mathrm{G} 2$ cell cycle delay in cancer cells lacking stathmin and p53. Cytoskeleton (Hoboken) 69: 278-289, 2012.

57. Tao W, South VJ, Zhang Y, Davide JP, Farrell L, Kohl NE, Sepp-Lorenzino L and Lobell RB: Induction of apoptosis by an inhibitor of the mitotic kinesin KSP requires both activation of the spindle assembly checkpoint and mitotic slippage. Cancer Cell 8: 49-59, 2005.

58. Maurer SP, Fourniol FJ, Bohner G, Moores CA and Surrey T: EBs recognize a nucleotide dependent structural cap at growing microtubule ends. Cell 149: 371-382, 2012.

59. Sandblad L, Busch KE, Tittmann P, Gross H, Brunner D and Hoenger A: The Schizosaccharomyces pombe EB1 homolog Mal3p binds and stabilizes microtubule lattice seam. Cell 127: 1415-1424, 2006

60. Pagano A, Honoré S, Mohan R, Berges R, Akhmanova A and Braguer D: Epothilone B inhibits migration of glioblastoma cells by inducing microtubule catastrophes and affecting EB1 accumulation at microtubule plus ends. Biochem Pharmacol 84: 432-443, 2012. 